Dilakshan, S., Rathnasinghe, A.P. and Seneviratne, L.D.I.P., 2021. Potential of internet of things (IOT) in the construction industry. In: Sandanayake, Y.G., Gunatilake, S. and Waidyasekara, K.G.A.S. (eds). Proceedings of the $9^{\text {th }}$ World Construction Symposium, 9-10 July 2021, Sri Lanka. [Online]. pp. 445-457. DOI: https://doi.org/10.31705/WCS.2021.39. Available from: https://ciobwcs.com/papers/

\title{
POTENTIAL OF INTERNET OF THINGS (IOT) IN THE CONSTRUCTION INDUSTRY
}

\author{
S. Dilakshan ${ }^{1}$, A.P. Rathnasinghe ${ }^{2}$ and L.D. Indunil P. Seneviratne ${ }^{3}$
}

\begin{abstract}
The introduction of the Internet of Things (IoT) in the manufacturing industry changed the trajectory to Industrial Revolution 4.0. Accordingly, it consists of various technologies, where the IoT is the basis of this revolution. However, there is an increasing gap between traditional Construction and digitalised data-driven Construction. In such context, the adoption of IoT applications in construction projects shall increase the productivity and better performance of construction activities. Consequently, IoT concepts, developments, applications, and potential benefits of IoT in the construction industry need to be acknowledged by industry practitioners before the implementation can take place. Hence, the purpose of this research is to outline such needs, thus provide an understanding on the potential of the IoT in the construction industry. Subsequently, a comprehensive literature synthesis revealed the expression IoT is best understood as a metaphor that encapsulates the immersion of almost anything and everything within the communications and connectivity space. The development is at an embryonic stage of development but proliferating in measuring, tracking, modelling, and prediction stages such as smart wearables, sensors attached to the structures and machinery, IoT linked Building information modelling (BIM) models, usage of drones. As a result, potential benefits are entertained by the construction industry practitioners towards sustainability. Ultimately, the study provides a starting point for raising awareness to facilitate and implement IoT applications in construction projects. In the absence of empirical literature on the implementation of the IoT paradigm in general, this paper presents a valuable contribution to the growing body of knowledge.
\end{abstract}

Keywords: Automation; Bottlenecks; Construction industry; Internet of Things (IoT); Smart controls.

\section{INTRODUCTION}

A telescope was invented after more than two hundred years, from the invention of the printing press in the $14^{\text {th }}$ century (Kodithuwaku, 2019). However, Kodithuwaku (2019) emphasises that today, Things being invented within months, where time gaps between inventions are being shortened. In line with this development, the Internet of Things is an area of innovation and growth (Vermesan and Friess, 2013). The development of the IoT concept would change lifestyles and enhance the industry's performance (Suriyarachchi et al., 2019). As a result, the construction industry will follow such rapid technological enhancements around the world.

\footnotetext{
${ }^{1}$ Department of Building Economics, University of Moratuwa, Sri Lanka, dilux96@ gmail.com

2 Department of Building Economics, University of Moratuwa, Sri Lanka, akilapr1993@gmail.com

${ }^{3}$ Department of Building Economics, University of Moratuwa, Sri Lanka, isenevi@uom.lk
} 
The IoT is massively significant to the built environment (Oesterreich and Teuteberg, 2016). Jones (2017) insisted that carpenters, welders, and painters on the worksite might not discuss the IoT in casual conversation. However, a growing number of industryleading contractors and builders are using IoT devices to monitor equipment, machinery, and workers to make better decisions in real time. Consequently, there are 367 IoT-related projects identified worldwide, whereas industrial-related is 265 , and IoT-related building projects are 193 (Lueth, 2019).

\section{RESEARCH PROBLEM}

Triax (2018) identified that the construction industry regularly suffers from bottlenecks, slowing down dramatically without supervisors knowing that is even happening. In the case of one company, where they lost $\$ 4$ million by labourers spending too much time waiting for the lift. Installing a second lift on day one would have cost them just $\$ 1$ million, which is the solution provided by an IoT device at the end of the day. The company could have adopted such a solution on the initial day if they had such technology to identify. Hence, that would not have had such a severe impact on their project (Triax, 2018).

Consequently, many countries are developing their IoT network in Construction. Therefore, the use of IoT applications and the potential of such applications in Construction need to be acknowledged by the Construction industry, as the industry will become ever more complicated in the future (Mahmud et al., 2018). In such a time, if there is no system for facilitation of the work involved, the construction sector must take account of the expansion of the IoT network; otherwise, the construction sector will be left behind by other industries.

Besides, IoT in a fledgeling stage, with a limited number of experts operating somewhat in isolation and offering single-point solutions; for instance, publications identified and the main focus of research undertaken to be in the technical areas of smart buildings, construction safety, and optimisation and simulation (Ghosh et al., 2020). Hence, a broader picture of applications needs to be outlined. Additionally, researches were conducted on the adoption of IoT specifically to several geographical construction contexts. Despite those restrictions, there was a necessity to bring the overall applications and benefits of IoT to the construction industry. Nevertheless, the benefits of IoT applications in the construction industry are still not clear (Chen et al., 2019). Therefore, the subject of the enquiry undertaken was to examine the applications of the IoT in global context; thus, this study aimed to illustrate the potential of IoT in the construction industry by addressing the IoT concepts, present applications, development categories, and benefits associated with it.

\section{RESEARCH METHOD}

To achieve the aim, this paper intends to bring in literature analysis and arguments on the following themes:

1. The concepts and current development categories of IoT identified in the global construction industry

2. IoT applications practised in the global construction industry

3. The potential benefits achieved from IoT applications in several construction contexts. 
The literature was searched based on unconstrained and unstructured iterative queries to explore the potential of IoT in the construction industry (Eiris and Gheisari, 2017). Accordingly, information from the peer-reviewed conference, journal papers, reports, forums, and dissertations were obtained from leading academic databases were examined such as Google Scholar, Web of Science, Science Direct/Scopus, EBSCOhost, IEEE Xplore, CuminCAD, JSTOR (Loyola, 2018). The generic descriptors "Internet of Things", "Construction 4.0", "Smart", and "Digital" were used to find relevant information in the construction field of study (Senanayake et al., 2020). The sources were slightly extended through a selective snowball method, as the need to deepen the review in complementary topics arose (Loyola, 2018). Besides, as decisions regarding inclusion and exclusion remain relatively subjective, this research is mainly focused upon an indepth investigation of literature sources. Accordingly, the selected papers were subjected to manual thematic analysis to develop findings against the developed themes. However, this study is limited to the sources which are readily available from databases. Consequently, IoT concepts, present applications, development categories, and benefits associated with it in the construction industry in the global construction context were outlined.

\section{INTERNET OF THINGS (IOT)}

The International Telecommunication Union (ITU, 2012) defined IoT as "A global infrastructure for the information society, enabling advanced services by interconnecting (physical and virtual) things based on existing and evolving interoperable information and communication technologies" (p. 6). Specifically, IoT is identified as a system of 'Things' using the Internet or a private network to connect and communicate with each other (Censis, 2019). In particular, 'Things' are stipulated as 'smart devices' connected to a network and communicate among each other with minimum human engagement (Phuoc et al., 2009). The basic idea is that objects of day-to-day life can be equipped with the detection, sensing, networking, and processing capabilities that enable them to communicate over the Internet with each other and with other devices and services to achieve a common goal (Dooley et al., 2017). In such context, the IoT allows people and Things to be connected anytime, anyplace, with anything and anyone, ideally using any path/network and any service (Balte et al., 2015). The system enables acquiring, processing, and reacting to real-world data in real-time (Lan et al., 2019).

\subsection{DEVELOPMENT CATEgORIES}

Presently, millions of IoT devices are communicating with each other. In addition, such devices tend to be negotiating, interacting, measuring, and responding with the least human involvement. Husain (2017) identified the development of IoT in three waves.

\subsubsection{First Wave: Measuring and Tracking}

Husain (2017) recognised that people are currently in the midst of the first wave of IoT. There are wearables and gadgets implemented to measure pulse rate and track day-to-day work activities, predict the circadian rhythm and automatically trigger the alarm if people fall asleep, and alarm in case of intruders in private places (Husain, 2017).

\subsubsection{Second Wave: Modelling and Predicting}

There are circumstances identified where data captured from the first wave of devices were used by devices to model the environment, their behaviour, and the behaviour of 
other systems to predict the future. Some systems include delivery drones, self-driving trucks and tractors, and increasingly sophisticated factory and warehouse bots that use vision to detect objects and sort products and packages (Husain, 2017).

\subsubsection{Third Wave: Fully Autonomous Devices}

IoT's maximum potential will be recognised in the third wave, where there will be federated network intelligence powering cognitive, fully autonomous devices. In such context, the humans who built such devices will not experience the reality of it. For instance, algorithms that empower fleets of hundreds of thousands of autonomous drones carry out an ever-increasing range of functions for their human owners (Husain, 2017).

\section{PRESENT APPLICATIONS OF IOT IN THE GLOBAL CONSTRUCTION INDUSTRY}

A new and fast-emerging shift in networking and communications is the IoT. Several contractors have already implemented IoT applications for both production and delivery of services in the construction industry to maximise their opportunities (Atayero et al., 2016). Accordingly, several applications were identified below.

\subsection{MeASURING AND TraCking APPLICATIONS}

In such context, Mehata et al. (2019) identified IoT- Designed smart wearable devices, such as bands and helmets, using different types of sensors to help track workers' health and safety. The devices are designed with the help of IoT, which detects any worker's fall and sends alert messages for emergency help. Besides, employees are frequently tracked and alert about adverse health problems, such as pulse rate and temperature (Ding et al., 2013).

In another context, abnormal changes in the underground water table, change in shape, load on external lateral support, and degree of sloping of supporting structural components are indications before structural failure. Such changes inevitably go beyond safety limits and potentially lead to structural failures. IoT real-time monitoring solutions are developed to detect and analyse such abnormal changes and issue appropriate warning signals to take remedial actions on time (Lam et al., 2017). Therefore, evacuation time would still be adequate to avoid accidents and casualties. Similarly, the IoT system was used to monitor a retaining wall movement in Shenzhen, China. Measurable cracks, in particular retaining walls and cracks created by differential settlement in the adjacent buildings, were identified in real-time. Subsequently, data showed a night-time surge in the rising level of the underground water table detected on the side of the retaining wall. The findings revealed that the drainage system experienced a significant leakage (Lam et al., 2017).

Bottaccioli et al. (2017) found a different scenario that the IoT system will represent the buildings' energy usage accounted for in real-time. Therefore, energy consumption monitoring improves energy efficiency, decreases waste, and is favourable to sustainable development (Wan et al., 2010).

On the other hand, green building is a reasonable assurance for sustainable growth. The Green building concept achieves its goals by using the IoT technology and cloud computing with the green building energy efficiency standards (Zhao et al., 2013). In 
such context, IoT carries out the overall environmental monitoring, provides supervision, managing, and data processing (Wang et al., 2017).

Nair (2020) mentioned the most intelligent building in the world called "The EDGE", which has 28,000 sensors installed under the IoT network. Such sensors collect property data and user data with the goal of increased user friendly.

Zhou and Ding (2017) pointed out the scenario of the twin tunnel project across Yangtze River, where during the transport of materials in $25 \mathrm{~m}$ depth of tunnel hole, the hazard energy restriction alarming scenario has occurred at the bottom. The gate crane driver at the top could not be able to see the circumstance at the bottom. The Radio-frequency identification (RFID) sensors on workers' helmets and sensors around this dangerous area triggered the warning. Accordingly, the regional workers were able to leave the hoisting field.

\subsection{Modelling ANd Predicting Applications}

In contrast, IoT technology influences the concrete production market. IoT based services for mounted batching plants can improve the consistency of concrete quality, connected logistics, and predictive maintenance (Walther, 2018). The batching plant is fitted with sensors such as weighing sensors and flowmeters to handle such measurements (Rasmussen and Beliatis, 2019). In such context, weighing sensors monitor the mixing of all aggregates and measure the weight of each aggregate. The flowmeter calculates the water rate in $\mathrm{kg} / \mathrm{sec}$ to the batch to maintain the appropriate mix of gravel and cement in the receipt.

In another case, the developed BIM model is available for steel bridge construction, which is directly linked with IoT for real-time data simulation for Construction (Zhang et $a l ., 2016)$. Such encouragement facilitating dynamic interactions and real-time responses among designers, builders, transit providers, and maintainers. Therefore, the integration of the value chain between stakeholders is possible, and the project's success is achieved (Ding et al., 2018).

In contrast, the type of precast components, the fabrication method of such components, the comprehensive construction process, cost, and quality of the completed steel bridge can be identified by attaching IoT labels on precast components (Zhong et al., 2015). Accordingly, steel-bridge performance can be monitored remotely in the construction stage. Thereafter, Big data analytics further evaluates sensor data into the decisionmaking model. Thereupon, the steel bridge can be predictively and proactively maintained (Ding et al., 2018).

KOMATSU introduced smart Construction, which links everything present on the site dynamically under IoT and allows 3D formation (Sategna et al., 2019). Furthermore, IoT applications are involved in using drones to conduct surveys high precisely and real-time observation of changing topography of worksites.

Kuenze et al. (2016) addressed, IoT system addresses all steps of the supply system, from asphalt batching to compaction of asphalt. Moreover, asphalt temperature can be regulated by temperature sensors in the truck at any time. The information from embedded sensors on asphalt plants and pavers allows for a just-in-time schedule of asphalt delivery services, thereby decreasing the number of dump trucks to be delivered at the site (Sategna et al., 2019). 
In another case, a contractor used swing stages to do external work on a high-rise building to get the job done. All the subcontractors required to access the stations, and the supervisors complained about not having enough stations and not being available at the time necessary. The work was slowed down accordingly. Later it is identified, with the support of IoT sensors attached to each platform, the supervisors on his smartphone were able to figure out where the lifts were and whether one was available instantly (Triax, 2018).

\subsection{Fully AUTONOMOUS APPLICATIONS}

Wu et al. (2018) found a situation on the application of IoT in a utility tunnel in Xiamen city, China. The project includes surrounding dust monitoring systems, automatic sprinkler dust falling control systems, and site temperature monitoring systems based on real-time metrological data. Hence, the tunnel operation and maintenance are visualised by data provided by IoT sensors (Bottaccioli et al., 2017). Data control of the dust is related to the spray dust reduction system. If the air quality is not up to standard, the device will issue a warning on the BIM model and open the spray dust control system automatically in the respective region (Teizer et al., 2017). Besides, BIM and IoT technologies often have essential applications such as limited space detection and gate management; thus, the gate can be controlled and operated remotely. Correspondingly, the gate can be automatically monitored and connected to the network to ensure better protection inside the utility tunnel (Patti and Acquaviva, 2016).

In another case, Smart contracts can remove the need for an authorised third party to administer a contract in an autonomous state by integrating BIM and the IoT. As a result, IoT will manage payment procedures with actual work progress. Afterward, the central iContract platform will evaluate all data against the agreed contract clause and enforce the terms accordingly (AIQS, 2019).

Therefore, seems to be numerous applications were identified by authors in measuring, tracking, modelling, and predicting waves that would have a significant impact on the construction industry. Besides, it seems the industry will reach more tremendous potential in the full autonomous wave.

\section{THE POTENTIAL BENEFITS OF IOT IN THE CONSTRUCTION INDUSTRY}

The construction industry value chain is profoundly affected by collaboration with major contractors to low-level suppliers. Besides, Construction projects are site-based and complex, requiring a higher-level management process (Oesterreich and Teuteberg, 2016). In such context, the emergence of the IoT makes a significant impact and brings several benefits for the projects and people involved. Accordingly, several authors identified consequences that emphasise the potential of IoT. Such consequences are recognised below.

\subsection{UP-TO-DATE INFORMATION FOR BETTER DECISION MAKING}

The IoT network consists of intelligent devices that are installed around the worksite, connected to vehicles, materials, and attached to workers (Bucchiarone et al., 2019). Besides, the IoT application handles all incoming information and provides supervisors with up-to-date information and alerts for particular events such as the system stops 
working and the process stage is completed, thereby allowing them to make suitable decisions (Piccialli et al., 2020).

\subsection{IMPROVED PROJECTS HANDLING WITH MINIMUM HUMAN EFFORT}

Construction sites of megaprojects have various workflows, according to the size and type of the project. In such context, a challenging task is to plan and organise such complex projects (Clough et al., 2000). Further, the lack of adequate digital and precise data requires a permanent project manager at a physical presence. Hence, IoT Network helps project managers to control several construction sites remotely at various locations simultaneously and to intervene quickly to adjust their activity to the effects of real-time data (I. Lee and Lee, 2015).

\subsection{Minimised Project Delay by Taken Preventive Measures}

Typically, the construction site is not prepared to face abnormal weather situations, and preventive mechanisms are not in place (Mohammed et al., 2014). Hence, the status of such a situation leads to the loss of money and downtime delays in the construction process. However, the IoT network's usage promptly alerts such bad weather by interacting with the meteorological station. Therefore, countermeasures can be taken on time (Wu et al., 2018).

\subsection{REMOTE OPERATION OF ACTIVITIES IN WORKSITE}

According to Burger (2017), if machines are remotely connected, instructions can be given from a long distance. Therefore, human resources can be removed from hazardous places. Besides, Nordin (2016) elaborated on such a situation with drones, that a machine easily identifiable by drone is eligible to obtain commands and operate alone under surveillance areas.

\subsection{IMPROVED SUPPLY CHAIN MANAGEMENT}

Through IoT, the system could measure the available stock by the RFID labels attached to materials. Therefore, the system will automatically produce alerts to maintain available stock (Burger, 2017). The RFID tags installed on the commodities inform about the adequacy of the item temperature, handling impact, damage level, and expiry period (Macaulay et al., 2015).

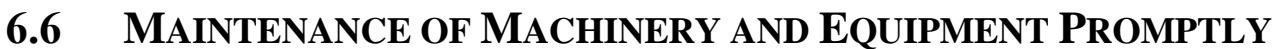

Maintenance of machinery is necessary to prevent additional expenses due to severe damage. The IoT allows sending information on the current state of tools and equipment in real-time to repair or maintain needs (Burger, 2017). According to Levy (2017), heavyduty construction machines are equipped with sensors, where such sensors can detect the required maintenance from range, such as temperature fluctuations and increased vibrations.

\subsection{Energy, Fuel, ANd PoWer SavingS}

Unmaintained energy and fuel usage will lead to wastage and affect the project cost. Through the approach of IoT, information about the usage of electricity, gas, generator fuel can be obtained from the building (EEI et al., 2011). Additionally, the use of tools and equipment will be controlled for fuel-saving requirements (ITU, 2015). 


\subsection{IMPROVED TRANSIT MANAGEMENT (TIME-SAVING)}

According to Cunha (2014), selecting inappropriate transit routes would lead to significant fuel usage and delay in the supply chain. Hence, sensors act as general packet radio service (GPRS) will provide operators with data about the most efficient and quick transit lines through the Internet of Things (Sategna et al., 2019).

\subsection{SECURITY CONTROL OF THE SITE}

There is a possibility for material theft at the site if the storage units are not adequately supervised (Said and Rayes, 2010). However, with the help of IoT, any material theft is easily solved using IoT labels since these sensors inform the current location of such materials (Macagnano et al., 2014). Furthermore, the IoT-developed security device known as August Smart Lock, which operates over Wi-Fi networks. This unit is placed at doors and provides control over doors through mobile devices. Moreover, such a device scans every object pass through doors and triggers an alarm when there are threats (Macaulay et al., 2015).

\subsection{Human ReSOURCE MANAGEMENT}

Firms need to make sure that employees work effectively and efficiently under considerations of third-party safety, obligations of the contract, and rules of the firm (Loosemore et al., 2003). Through the IoT application, sensors attached to the employees' uniform are enabled to notify the supervisor of their presence, abilities, and credentials for the task and the time they spend on particular activities (Häikiö et al., 2020). Furthermore, such data from IoT used for human resource development and payment procedures (Cunha, 2014).

\subsection{ENVIRONMENTAL MONITORING}

Libelium (2012) identified there are devices developed with the concept of IoT to monitor environmental aspects. Such devices consist, a remote-control sensor capable of monitoring fire, flood threats, and air pollution. Subsequently, they interact with relevant protocols to take preventive measures.

\subsection{HeAlth MONITORING OF STRUCTURES}

Libelium (2012) reported that the IoT is used for the building's health and safety by installing sensors on structures sensitive enough to detect vibrations, cracks, and defects in building components.

\subsection{WASTE MANAGEMENT}

A smart waste management scheme was launched as an IoT solution using infrared sensors, microprocessors, and remote accessories (Zeinab and Elmustafa, 2017). The particular program ensures that the garbage is removed automatically when the waste hits full. The condition will be reported to relevant authorities for necessary action if the trash has not been removed for a while.

\subsection{ECONOMIC BENEFIT}

IoT increases interconnectivity among people and Things. Hence, it drives the economy much higher and provides more wealth (Manyika and Roxburgh, 2011). 


\subsection{IDENTIFICATION OF FlaWS IN CONSTRUCTION PHASES}

In the use of IoT, potential weaknesses can be identified at all stages of the construction process by gathering, assimilating, and connecting data of all operations at the worksite (Sategna et al., 2019).

\subsection{NEW OPPORTUNITIES AND SOLUTIONS}

In the future of Construction, everything will be connected at the site (Yuanyuan et al., 2006). Data arising from such environments will be available on cloud platforms to further develop integrated services and solutions for different project stages (Bottaccioli et al., 2017).

\subsection{OTHER KEY BENEFITS}

Accordingly, Yuqiang et al. (2010) identified, the purpose of such advancement enables all Things to be interpreted and remotely controlled and integrated with the Internet into a more intelligent system of life and development. Hence, the system can solve technical problems in industries, improve work management, enhance resource utilisation, and improve the relationship between humans and nature (Chao-sheng, 2012). Furthermore, key benefits are summarised in Table 1 .

Table 1: Benefits from IoT

\begin{tabular}{|c|c|}
\hline Benefit & Description \\
\hline Efficiency & Better use of time; speed up processes \\
\hline Productivity & Identify and eliminate process errors \\
\hline Profitability & $\begin{array}{l}\text { Cost savings and increased productivity leads to increased } \\
\text { profitability }\end{array}$ \\
\hline Compliance & $\begin{array}{l}\text { New and more effective ways to monitor and report compliance } \\
\text { requirements }\end{array}$ \\
\hline Safety & People exposed to less hazardous environments \\
\hline Society & Monitoring for health and social care \\
\hline Environment & Maintenance of pollution levels, air quality, flooding alerts \\
\hline Innovation & New products and service opportunities or new markets \\
\hline Business Intelligence & $\begin{array}{l}\text { Allowing the gathering of data to make better decisions to benefit } \\
\text { the organisation }\end{array}$ \\
\hline
\end{tabular}

(Source: Censis, 2019)

Therefore, it seems to be those potential benefits of IoT would bring greater sustainability through better utilisation of resources and improvements to the construction industry. Hence, it will lead to strategic, structural \& cultural transformations towards the new normal.

\section{CONCLUSIONS AND WAY FORWARD}

This study uncovers and identifies, and assesses the IoT concepts, applications, and potential in the construction industry by bringing literal identification from significant authors. Accordingly, the concept of "IoT" seems to be widely adopted, with three features: the live-time tracking of "Things" conducted actively by different types of 
sensors; linking such smart objects to a worldwide network through widespread internet technologies and utilising such technologies to develop smart "Things" controls. However, the development of IoT applications is still in the measuring, tracking, and modelling stage out of its maximum potential of autonomous applications. It is further evidenced by the identification of several present applications of IoT in the global construction industry. Moreover, significant benefits identified from such prospective scenarios emphasise IoT's potential impact in the construction industry. Besides, it is an indication that many have adopted the technology and put it into practice.

In addition, there are potential benefits of applying IoT in construction projects addressed through different contexts of applications. Hence, it emphasises the IoT has the potential to solve the problems utilisation of resources and improve the working methods incorporated in the construction industry. Consequently, the overall potential of IoT has been established. Accordingly, industry practitioners and internal, external stakeholders should develop innovative attitudes and flexibility to adopt new practices; thus, this study can achieve maximum benefit. Additionally, this new creation of explicit knowledge of this study shall be acknowledged by professional institutions to raise awareness in the construction industry. The government agencies, stakeholders and policymakers shall refer to this study to get the point of reference in directing the IoT's adoption smoothly in the construction sector.

\section{REFERENCES}

AIQS, 2019. Building Economist. [Online] Available from: https://www.aiqs.com.au/sites/default/files/uploaded-content/field_f_magazine_upload/tbe19jun.pdf [Accessed 4 June 2021].

Atayero, A.A., Oluwatobi, S.O. and Alege, P.O., 2016. An assessment of the Internet of Things (IoT) adoption readiness of Sub-Saharan Africa. Journal of South African Business Research, 13, pp. 1-13.

Balte, A., Kashid, A. and Patil, B., 2015. Security issues in Internet of Things (IoT): A survey. International Journal of Advanced Research in Computer Science and Software Engineering, 5(4), pp. 450-455.

Bottaccioli, L., Aliberti, A., Ugliotti, F., Patti, E., Osello, A., Macii, E. and Acquaviva, A., 2017, July. Building energy modelling and monitoring by integration of IoT devices and building information models. In 2017 IEEE $41^{\text {st }}$ Annual Computer Software and Applications Conference (COMPSAC), Vol. 1, pp. 914-922. IEEE.

Bucchiarone, A., De Sanctis, M., Hevesi, P., Hirsch, M., Abancens, F.J.R., Vivanco, P.F., Amiraslanov, O. and Lukowicz, P., 2019. Smart construction: remote and adaptable management of construction sites through IoT. IEEE Internet of Things Magazine, 2(3), pp. 38-45.

Burger, R., 2017. How "The Internet of Things" is affecting the construction industry. The Balance Small Business.

Censis, 2019. Getting started with IoT: Exploring IoT (Internet of Things) for business growth [Brochure], Glasgow: Censis.

Chao-Sheng, H., 2012. Issues and countermeasures of the internet of things in the view of low-carbon economy. In 2012 Second International Conference on Business Computing and Global Informatization, pp. 461-464. IEEE.

Chen, J.H., Ha, N.T.T., Tai, H.W. and Chang, C.A., 2019. The willingness to adopt the Internet of things (IoT) conception in Taiwan's construction industry. Journal of Civil Engineering and Management, 26(6), pp. 1-17.

Clough, R. H., Sears, G.A. and Sears, S. K., 2000. Construction project management. WILEY.

Cunha, L., 2014. Building with the internet of things in the construction industry. 25 February, 2014. [Online] Available from: https://www.to-increase.com/internet-of-things-construction. 
Ding, K., Shi, H., Hui, J., Liu, Y., Zhu, B., Zhang, F. and Cao, W., 2018. Smart steel bridge construction enabled by BIM and Internet of Things in industry 4.0: A framework. In 2018 IEEE 15th International Conference on Networking, Sensing and Control (ICNSC), pp. 1-5. IEEE.

Ding, L.Y., Zhou, C., Deng, Q.X., Luo, H.B., Ye, X.W., Ni, Y.Q. and Guo, P., 2013. Real-time safety early warning system for cross passage construction in Yangtze Riverbed Metro Tunnel based on the internet of things. Automation in Construction, 36, pp. 25-37.

Dooley, K., Ihasalo, H., Jylhä, T. and Sairanen, S., 2017. IoT market analysis in the Finnish estate and construction sector: Market analysis, Finland: Granlund.

EEI, AEIC and UTC, 2011. A discussion of smart meters and RF exposure issues, Washington, D.C: Edison Electric Institute.

Eiris, R. and Gheisari, M., 2017. Research trends of virtual human applications in architecture, engineering and construction. Journal of Information Technology in Construction, 22, pp.168-184.

Ghosh, A., Edwards, D.J. and Hosseini, M.R., 2020. Patterns and trends in Internet of Things (IoT) research: Future applications in the construction industry. Engineering, Construction and Architectural Management, 28(2), pp. 457-481.

Häikiö, J., Kallio, J., Mäkelä, S.M. and Keränen, J., 2020. IoT-based safety monitoring from the perspective of construction site workers. International Journal of Occupational and Environmental Safety, 1, pp. $1-14$.

Husain, A., 2017. The sentient machine: The coming age of artificial intelligence. New York: Scribner.

ITU (2012). ITU-T Recommendations [Online]. Available from: http://handle.itu.int/11.1002/1000/11559 [Accessed 4 June 2021].

ITU, 2015. GSR discussion paper: Regulation and the Internet of Things, Geneva: Author.

Jones, S., 2017. Safety management in construction industry, Bedford: DODGE Data \& Analytics.

Kodithuwaku, M., 2019. Industry 4.0 \& construction 4.0. Colombo, Institute of Quantity Surveying Sri Lanka, pp. 21- 31.

Kuenze, R., Teizer, J., Mueller, M. and Blickle, A., 2016. SmartSite: Intelligent and autonomous environments, machinery, and processes to realize smart road construction projects. Automation in Construction.

Lam, R.C.Y., Junus, A., Cheng, W.M.Y., Li, X. and Lam, L.C.H., 2017. IoT application in construction and civil engineering works. In 2017 International Conference on Computational Science and Computational Intelligence (CSCI), pp. 1320-1325. IEEE.

Lan, L., Shi, R., Wang, B., Zhang, L. and Jiang, N., 2019. A universal complex event processing mechanism based on edge computing for internet of things real-time monitoring. IEEE Access, 7, pp. 101865101878.

Lee, I. and Lee, K., 2015. The Internet of Things (IoT): Applications, investments, and challenges for enterprises. Business Horizons, 58(4), pp. 431-440.

Le-Phuoc, D., Polleres, A., Hauswirth, M., Tummarello, G. and Morbidoni, C., 2009, April. Rapid prototyping of semantic mash-ups through semantic web pipes. In Proceedings of the $18^{\text {th }}$ international conference on World wide web, pp. 581-590.

Levy, J., 2017. 4 big ways the IoT is impacting design and Construction [Online]. IBM. Available from: https://www.ibm.com/blogs/internet-of-things/4-big-ways-the-iot-is-impacting-design-andconstruction/

Libelium, 2012. 50 sensor applications for a smarter world [Online]. Available from: https://www.libelium.com/libeliumworld/top_50_iot_sensor_applications_ranking/

Loosemore, M., Dainty, A. and Lingard, H., 2003. Human resource management in construction projects: Strategic and operational approaches. London: Routledge.

Loyola, M. 2018. Big data in building design: a review. Journal of Information Technology in Construction (ITcon), 23, pp. 259-284.

Lueth, K. L., 2019. IoT platform companies' landscape 2019/2020: 620 IoT platforms globally. Hamburg, Germany: IoT-analytics.

Macagnano, D., Destino, G. and Abreu, G., 2014. Indoor positioning: A key enabling technology for IoT applications. In 2014 IEEE World Forum on Internet of Things (WF-IoT), pp. 117-118. IEEE. 
Macaulay, J., Buckalew, L. and Chung, G., 2015. Internet of things in logistics, Germany: DHL.

Mahmud, S. H., Assan, L. and Islam, R., 2018. Potentials of Internet of Things (IoT) in Malaysian construction industry. Annals of Emerging Technologies in Computing (AETiC), 2(4), pp. 44-52.

Manyika, J. and Roxburgh, C., 2011. The great transformer: The impact of the Internet on economic growth and prosperity. McKinsey Global Institute.

Mehata, K.M., Shankar, S.K., Karthikeyan, N., Nandhinee, K. and Hedwig, P.R., 2019, April. IoT based safety and health monitoring for construction workers. In $20191^{\text {st }}$ International Conference on Innovations in Information and Communication Technology (ICIICT), pp. 1-7. IEEE.

Mohammed, N., Alshebani, and Wedawatta, G., 2014. Making the construction industry resilient to extreme weather: Lessons from Construction in hot weather conditions. Procedia Economics and Finance, 18, pp. 635-642.

Nair, R., 2020. Build smarter spaces! Know 2019's top intelligent building trends [Online]. Available from: https://gbmme.com/newsroom/build-smarter-spaces-know-2019s-top-intelligent-building-trends/

Nordin, R., 2016. The Internet of Things, Author.

Oesterreich, T.D. and Teuteberg, F., 2016. Understanding the implications of digitisation and automation in the context of Industry 4.0: A triangulation approach and elements of a research agenda for the construction industry. Computers in Industry, 83, pp.121-139.

Patti, E. and Acquaviva, A., 2016. IoT platform for Smart Cities: Requirements and implementation case studies. Bologna: IEEE.

Piccialli, F., Casolla, G., Cuomo, S., Giampaolo, F. and Di Cola, V.S., 2019. Decision making in IoT environment through unsupervised learning. IEEE Intelligent Systems, 35(1), pp.27-35.

Rasmussen, N.V. and Beliatis, M.J., 2019. IoT based digitalization and servitization of construction equipment in concrete industry. In 2019 Global IoT Summit (GIoTS), pp. 1-4. IEEE.

Said, H. and Rayes, K.E., 2010. Optimizing the planning of construction site security for critical infrastructure projects. Automation in Construction, 19(2), pp. 221-234.

Sategna, L.G., Meinero, D. and Volontà, M., 2019. Digitalising the Construction Sector, pp.1-100.

Senanayake, G.P.D.P., Hadiwattage, C. and Sirimewan, D.C. 2020. Assuring sustainable construction through project feasibility evaluation criteria: A literature review. In: $17^{\text {th }}$ International Conference on Business Management. University of Sri Jayewardenepura.

Suriyarachchi, C., Waidyasekara, K. and Madhusanka, N., 2019. Integrating Internet of Things (IoT) and facilities manager in smart buildings: A conceptual framework. The $7^{\text {th }}$ World Construction Symposium 2018: Built Asset Sustainability: Rethinking Design Construction and Operation, 29 June - 01 July. Colombo, Sri Lanka, pp.325-334.

Teizer, J., Wolf, M., Golovina, O., Perschewski, M., Propach, M., Neges, M. and König, M., 2017. Internet of Things (IoT) for integrating environmental and localization data in Building Information Modeling (BIM). In ISARC. Proceedings of the International Symposium on Automation and Robotics in Construction, Vol. 34. IAARC Publications.

Triax, 2018. Demystifying the Internet of Things for construction, Norwalk: Author.

Vermesan, O. and Friess, P., 2013. Internet of things: Converging technologies for smart environments and integrated ecosystems. Aalborg: River Publishers.

Walther, T., 2018. Digital transformation of the global cement industry. Nashville: IEEE.

Wang, M., Qiu, S., Dong, H. and Wang, Y., 2017. Design an IoT-based building management cloud platform for green buildings. In 2017 Chinese Automation Congress (CAC), pp. 5663-5667. IEEE.

Wan, L., Sun, D. and Deng, J., 2010. Application of IOT in building energy consumption supervision. In 2010 International Conference on Anti-Counterfeiting, Security and Identification, pp. 169-172. IEEE.

Wu, C.M., Liu, H.L., Huang, L.M., Lin, J.F. and Hsu, M.W., 2018. Integrating BIM and IoT technology in environmental planning and protection of urban utility tunnel construction. In 2018 IEEE International Conference on Advanced Manufacturing (ICAM), pp. 198-201. IEEE.

Yuanyuan, Z., Jia, X. and Yanxiang, H., 2006. Energy efficient distributed connected dominating sets construction in wireless sensor networks. In: IWCMC '06 - 2006 International Wireless Communications and Mobile Computing Conference, Vancouver, Canada 3-6 July 2006. pp.797-802. 
Yuqiang, C., Jianlan, G. and Xuanzi, H., 2010. The research of internet of things' supporting technologies which face the logistics industry. In 2010 International Conference on Computational Intelligence and Security, Nanning, China, 11-14 December 2010. IEEE. pp.659-663

Zeinab, K.A.M. and Elmustafa, S.A.A., 2017. Internet of things applications, challenges and related future technologies. World Scientific News, 2(67), pp. 126-148.

Zhang, F., Liu, M., Zhou, Z. and Shen, W., 2016. An IoT-based online monitoring system for continuous steel casting. IEEE Internet of Things Journal, 3(6), pp.1355-1363.

Zhao, J., Zheng, X., Dong, R. and Shao, G., 2013. The planning, Construction, and management toward sustainable cities in China needs the environmental Internet of Things. International Journal of Sustainable Development \& World Ecology, 20(3), pp.195-198.

Zhong, R.Y., Lan, S., Xu, C. and Dai, Q., 2015. Visualization of RFID-enabled shopfloor logistics Big Data in cloud manufacturing. International Journal of Advanced Manufacturing Technology, 84, pp.14.

Zhou, C. and Ding, L.Y., 2017. Safety barrier warning system for underground construction sites using Internet-of-Things technologies. Automation in Construction, 83, pp.372-389. 